\title{
Comparison of the crystal structure and function to wild-type and His25Ala mutant human heme oxygenase-1
}

\author{
WEN-PU ZHOU ${ }^{1,2 *}$, WEN-WEI ZHONG ${ }^{1 *}$, XUE-HONG ZHANG ${ }^{2}$, \\ JIAN-PING DING ${ }^{3}$, ZI-LI ZHANG ${ }^{4}$ and ZHEN-WEI XIA ${ }^{1}$ \\ ${ }^{1}$ Ruijin Hospital Affiliated to School of Medicine, Shanghai Jiao Tong University, Shanghai $200025 ;{ }^{2}$ School of Life \\ Science and Technology, Shanghai Jiao Tong University, Shanghai 200030; ${ }^{3}$ Institute of Biochemistry and Cell Biology, \\ Shanghai Institutes for Biological Sciences, Chinese Academy of Sciences, Shanghai 200031, P.R. China; \\ ${ }^{4}$ Department of Pediatrics, Oregon Health and Sciences University, Portland, OR 97239, USA
}

Received October 29, 2008; Accepted December 12, 2008

DOI: 10.3892/ijmm_00000142

\begin{abstract}
Human heme oxygenase-1 (hHO-1) is a rate-limiting enzyme in heme metabolism. It regulates serum bilirubin level. Site-directed mutagenesis studies indicate that the proximal residue histidine 25 (His25) plays a key role in hHO-1 activity. A highly purified hHO-1 His25Ala mutant was generated and crystallized with a new expression system. The crystal structure of the mutant was determined by X-ray diffraction technology and molecular replacement at the resolution of $2.8 \AA$, and the model of hHO-1 His25Ala mutant was refined. The final crystallographic and free R factors were 0.245 and 0.283 , respectively. The standard bond length deviation was $0.007 \AA$, and the standard bond angle deviation was $1.3^{\circ}$. The mutation of His 25 to Ala led to an empty pocket underneath the ferric ion in the heme, leading to loss of binding iron ligand. Although this did not cause an overall structural change, the enzymatic activity of the mutant hHO-1 was reduced by $90 \%$. By supplementing imidazole, the HO- 1 activity was restored $\sim 90 \%$ to its normal level. These data suggest that Ala25 remains unchanged in the structure compared to His25, but the important catalytic function of hHO-1 is lost. Thus, it appears that His 25 is a crucial residue for proper hHO-1 catalysis.
\end{abstract}

\section{Introduction}

Heme oxygenase (HO) is a membrane-bound protein that facilitates the catabolism of heme in conjunction to coenzyme

Correspondence to: Dr Zhen-Wei Xia, Department of Pediatrics, Ruijin Hospital, 197 Ruijin 2nd Road, Shanghai 200025, P.R. China E-mail: xzw63@hotmail.com

${ }^{*}$ Contributed equally

Key words: human heme oxygenase-1, mutant, crystal structure, activity
NADPH-cytochrome P-450 reductase. HO converts heme to carbon monoxide $(\mathrm{CO})$, ferric ion and biliverdin which can further metabolize to bilirubin (1) by biliverdin reductase.

$\mathrm{HO}$ was once thought of as a rate-limiting enzyme only for heme metabolism and maintaining dynamic balance of intracellular hemoglobin. Its degradation products, including biliverdin, ferric ion and $\mathrm{CO}$, were considered toxic. However, recent research demonstrated that these metabolites actually exert important biological functions. HO activity is critical for maintaining the ferric ion cycle and provides iron required by the human body (2). Biliverdin and bilirubin are two well known antioxidants $(3,4)$. Although there is controversy regarding the biological function of $\mathrm{CO}(5), \mathrm{CO}$ is implicated in neural conduction $(6,7)$, protection of hemorrhagic shock (8), and regulation of microvascular contractility (9).

In addition to mammals, $\mathrm{HO}$ is expressed in bacteria and plants. $\mathrm{HO}$ was initially considered the terminal oxidase in the cytochrome P450 enzyme system (10). Now it is known as an enzyme independent of cytochrome P450 (11). In fact, HO is not a hemoprotein. However, it can interact with heme, forming a complex (12) in which heme acts as both a substrate and a coenzyme. Similar to a hemoprotein, the complex is composed of $\mathrm{HO}$ and heme that contains trivalent iron. The absorption spectrum of $\mathrm{HO}$ is comparable to metmyoglobin and methemoglobin. Heme degradation catalyzed by $\mathrm{HO}$ complex resembles the oxidation reactions of myoglobin or hemoglobin with ascorbic acid (13).

In mammalian cells there are at least two HO isomers, HO-1 and -2 , which are encoded by different genes. Another isomer HO-3, cloned only in rat, presents several mismatches in the heme signature motif, resulting in lower heme catalytic activity (14). HO-1 is an inducible enzyme with 288 amino acids total and is called heat shock protein 32 (15). HO-1 is induced by oxidative stress such as heme, heat shock, endotoxin, hydrogen peroxide, cytolysin, ultraviolet, heavy metals, and $\mathrm{CO}$ (16-18). HO-1 expression is mainly regulated at a transcription level. HO-1 exists in a variety of tissues, but is predominant in the liver and spleen. Lack of HO-1 leads to growth delay, anemia, and endothelial cell injury $(19,20)$. It is reported that HO-1 can inhibit inflammatory response (21) and allograft rejection $(22,23)$. Human HO-2 contains 316 amino 
acids. It is a constitutive enzyme highly expressed in the brain and testis. Its main catalytic product is $\mathrm{CO}$ which is considered likely to be involved in signal transduction pathways $(3,24)$. Compared to HO-1, HO-2 has an additional sequence segment at the $\mathrm{N}$-terminus.

The histidine (His) residue at position 25 (His25) plays an important role in forming a unique HO-1 complex with fivecoordinated ferric heme molecules $(25,26)$. Replacement of histidine with alanine (His25Ala) upregulates the activity of catalase and the level of intracellular glutathione, thereby enhancing the resistance to organic or inorganic peroxides. This is different from wild-type HO-1 (27). The study of the crystal structure of His25Ala mutant human heme oxygenase-1 (hHO-1) may provide an in depth understanding of its catalytic mechanism.

\section{Materials and methods}

Reagents. pET28b(+) and Escherichia coli BL21 (DE3) were purchased from Novagen (Madison, WI). Ni-NTA Superflow Cartridge was purchased from Qiagen (Hilden, Germany). Superdex-75 HR 16/60 column was purchased from GE Healthcare (Uppsala, Sweden). T4 DNA ligase, restriction enzymes, and Taq DNA polymerase were purchased from Takara (Dalian, China). Wild-type and His25Ala mutant hHO-1 expression plasmids pBHO-1(w) and (m) were constructed in our laboratory. All other chemicals used were of analytical reagent grade.

Construction of recombinant prokaryotic-expressing vector. In order to obtain His-tag fusion protein of 233-amino acid HO-1, PCR was performed using pBHO-1(w) and (m) as templates of wild-type and mutant $\mathrm{HO}-1$. PCR primer pairs of wild-type (sense: 5'-GAC AGC ATG CCC CAG GAT TTG TCA GAG GCC CTG AAG GAG GCC ACC AAG GAG GGC ACA CCC-3', antisense: 5'-AAC AGC TAT GAC CAT G-3' ) and mutant HO-1 (sense: 5'-GGA CAA TCC ATG GAG CGT CCG CAA CCC GAC-3', antisense: 5'-GCT AGA AGC TCG AGT GCC CGT GAG GGG CTC TG-3', containing NcoI and XhoI site) were synthesized by Shanghai Bio-Asia Biotech Co. (Shanghai, China). PCR mixture $(50 \mu \mathrm{l})$ contained $50 \mathrm{ng}$ templates, 150 pmol primers, $3 \mu \mathrm{mol} / \mathrm{l} \mathrm{dNTPs}, 1 \mu \mathrm{l}(10 \mathrm{U}) \mathrm{DNA}$ polymerase, $20 \mathrm{mmol} / 1$ Tris- $\mathrm{HCl}$ (pH 8.4), $10 \mathrm{mmol} / \mathrm{l} \mathrm{KCl}$, and $2 \mathrm{mmol} / 1 \mathrm{MgSO}_{4}$. The PCR condition was $94^{\circ} \mathrm{C}$ for 10 min for predenaturation, followed by 30 cycles at 94,65 , and $72^{\circ} \mathrm{C}$ for 1 min each and final extension at $72^{\circ} \mathrm{C}$ for $10 \mathrm{~min}$. The PCR product and Histagged fusion expression plasmid pET28b(+) were digested with NcoI and XhoI. The fragments of interest were isolated with agarose gel and ligated by T4 DNA ligase. After ligation, the expression plasmids pET28b(+)-HO-1(w) and (m) were verified by DNA sequencing.

Protein expression and purification. HO-1 expression plasmids were transfected into competent BL21 (DE3) cells by electroporation. The positive clones were grown in $2 \mathrm{xYT}$ medium containing kanamycin at $37^{\circ} \mathrm{C}$ for $12-16 \mathrm{~h}$. After reaching the concentration at $\mathrm{OD}_{600}$ of $0.5-0.8,1 \mathrm{mM}$ isopropyl $\beta-\mathrm{D}-1-$ thiogalactopyranoside (IPTG, Sigma) was added to induce protein expression for $16 \mathrm{~h}$ at $37^{\circ} \mathrm{C}$. The cells were collected by centrifugation and resuspended in $50 \mathrm{ml}$ of extraction buffer (20 mM sodium phosphate, $0.5 \mathrm{M} \mathrm{NaCl}, \mathrm{pH}$ 7.4). The cell suspension was sonicated on ice for $10 \mathrm{sec}$ in a 10 -sec interval with Xingzhi Y96-II sonic dismembrator (Ninbo, China) set at $400 \mathrm{~W}$. Cellular debris was removed by centrifugation at $13,000 \mathrm{rpm}$ for $40 \mathrm{~min}$. The supernatant was purified by chromatography. Briefly, the purified lysate was applied to the Ni-NTA-fast flow column (Qiagen, Hilden, Germany) that was equilibrated with $20 \mathrm{mM}$ sodium phosphate at $\mathrm{pH}$ 7.4. After washing off unbound proteins, retained proteins were eluted using a linear gradient of imidazole over a 5-column volume. The purity was assessed by SDS-PAGE gel electrophoresis. The proteins were then concentrated using Amicon ultra centrifugal filter device (Millipore, Bedford, MA) and loaded on Superdex-75 HR 16/60 column equilibrated with $20 \mathrm{mM}$ sodium phosphate at $\mathrm{pH}$ 7.4. The proteins were eluted using linear gradient of imidazole again. The purified proteins were concentrated using the Amicon ultra centrifugal filter device to $40 \mathrm{mM}$. The purity was re-assessed by $14 \%$ SDS-PAGE analysis.

hHO-1 activity assay. hHO-1 activity assay was performed as described previously with minor modifications (28). Briefly, the reaction mixture contained $40 \mathrm{mM}$ fusion proteins of wild-type or mutant hHO-1 fragments, $50 \mu \mathrm{M}$ heme (Fluka, USA), $5 \mathrm{mg} / \mathrm{ml}$ liver cytosol (source of biliverdin reductase), 1 U glucose-6-phosphate dehydrogenase, $2 \mathrm{mM}$ 6-phosphogluconate, $0.8 \mathrm{mM}$ NADPH, and $0.1 \mathrm{mM}$ potassium phosphate buffer ( $\mathrm{pH} \mathrm{7.4)}$ to $0.5 \mathrm{ml}$. The mixture reacted at $37^{\circ} \mathrm{C}$ for $30 \mathrm{~min}$ followed by ceasing the reaction on ice. The samples were scanned with spectrophotometer (Shima-dzu, Tokyo, Japan) at 464 to $530 \mathrm{~nm}$. Bilirubin concentration was calculated based on change of optical density from 530 to $464 \mathrm{~nm}$, with an extinction coefficient of $40 \mathrm{mM}^{-1} \mathrm{~cm}^{-1}$. Heme oxygenase activity was expressed as nanomole of bilirubin per milligram of protein per hour (nM bilirubin $\mathrm{mg}_{\text {protein }}{ }^{-1} \mathrm{~h}^{-1}$ ). In some experiments, imidazole $(10 \mathrm{mM})$ was added to the mixture to restore the enzymatic activity of hHO-1. The recovery of hHO-1 activity was measured at the end of reaction.

Crystal culture of hHO-1 and its mutant. The crystal culture method of wild-type hHO-1 and its mutant was based on the method by Schuller et al, with some modifications (29). The hanging drop vapor diffusion method was used for crystal growth. The protein sample was dissolved in $20 \mathrm{mM}$ potassium phosphate buffer $\left(\mathrm{pH} \mathrm{7.4)}\right.$ ) and centrifuged at $4{ }^{\circ} \mathrm{C}$, $10,000 \mathrm{rpm}$ for $10 \mathrm{~min}$ to a concentration of $40 \mathrm{mg} / \mathrm{ml}$. The crystallization buffer contained $2.12 \mathrm{M}$ ammonium sulfate, 0.1 M HEPES with a pH of 7.5 and $0.9 \%$ 1,6-isobutanol. Proteins $(2 \mu 1)$ were mixed with the same volume of crystallization buffer, balanced by $500 \mu \mathrm{l}$ crystallization buffer and cultured at $4^{\circ} \mathrm{C}$.

Collection of crystal X-ray diffraction data. Identification of initial diffraction of protein crystal and collection of diffraction data were both carried out on the Rigaku diffractometer (Rigaku, Japan). Crystals of an approprate size, obtained from Hampton Cryoloop, were rapidly immersed in crystallization buffer containing 35\% frozen protector D-(+)-trehalose, and quickly frozen in liquid nitrogen, then transferred to a rotary 
A

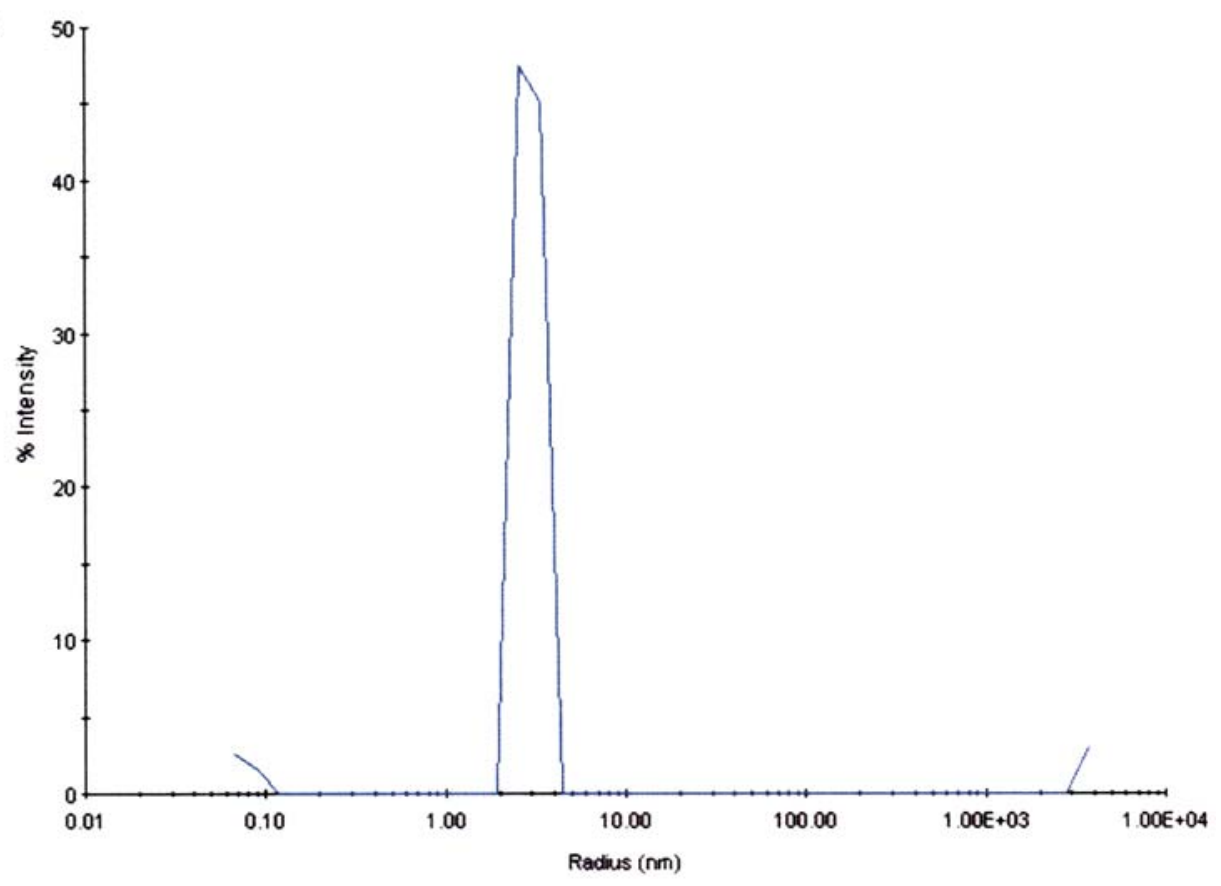

B

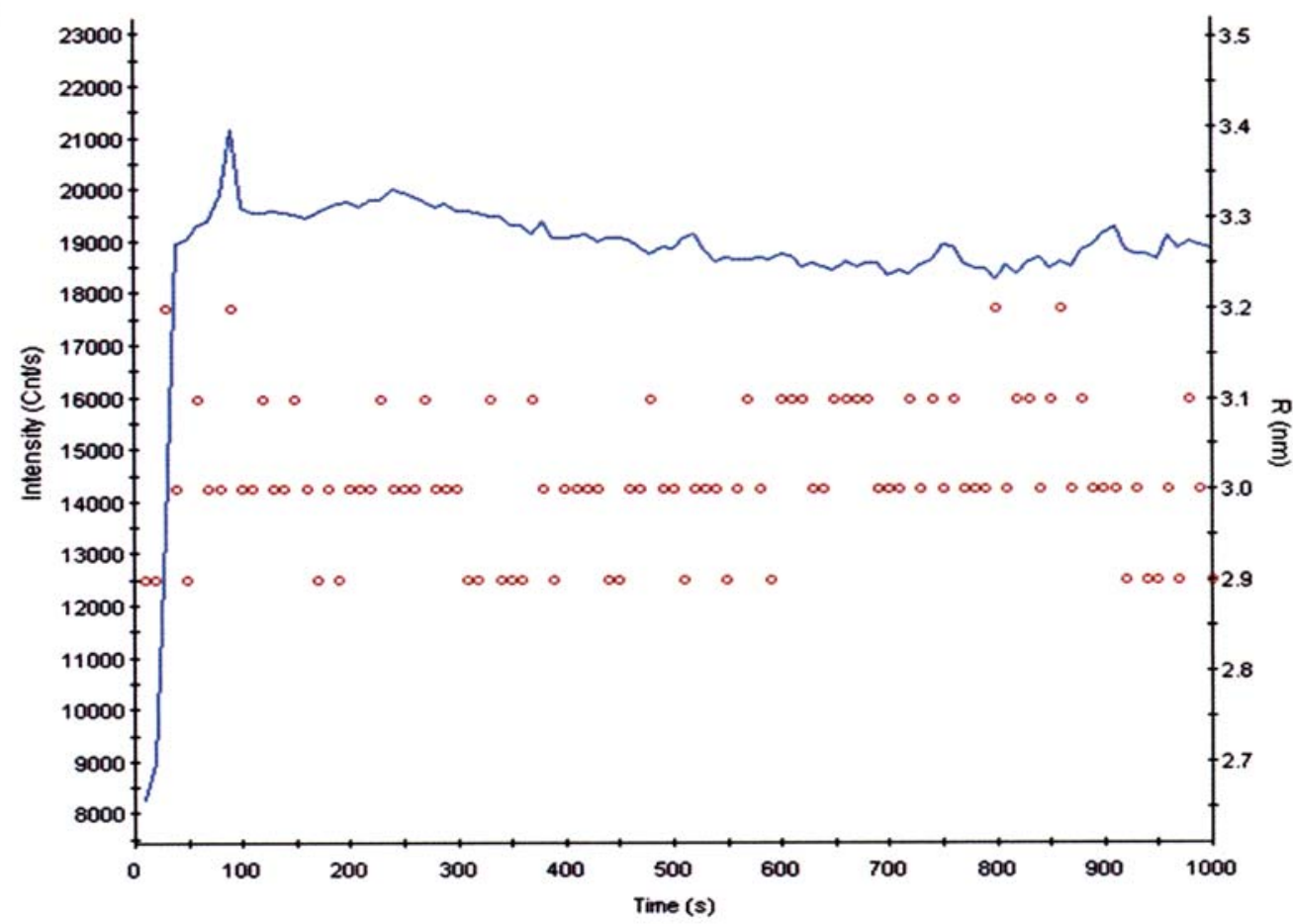

Intensity (Cnt/s)

- $R(n m)$

Figure 1. (A) Laser dynamic light scattering analysis of protein samples. (B) After laser dynamic light scattering, inspection revealed that the purified protein is well distributed in the solution.

angle head, protected by a $-180^{\circ} \mathrm{C}$ airflow. The swing angle of each diffraction image was between $0.5-1^{\circ}$, and the exposure time was between 2-4 min. The diffraction data were integrated and normalized with CrystalClear (30).

Determination and refinement of the structure. Using the crystal structure (1 NI6) of wild-type heme-HO-1 as a template, the His25Ala hHO-1 homologous model was constructed for which the His25Ala hHO-1 crystal structure was analyzed and obtained with molecular replacement method by Crystallography \& NMR System (CNS) (31). The structure refinement was achieved using the CNS software set to take the gradient energy minimization correction of stereochemistry constrained atomic locations and the atomic temperature factor correction. Five percent of the diffraction data in refinement were neglected in the $\mathrm{R}_{\text {free }}$ calculation. The correction result combined with SigmaA-weighted different maps and simulated annealing composite omit maps $(2 \mathrm{Fo}-\mathrm{Fc})$ were tested 


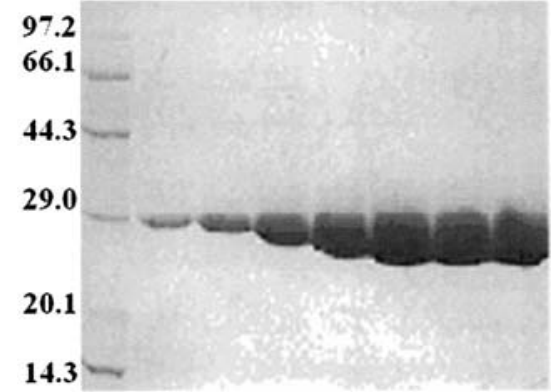

Figure 2. Determination of the protein purity of wild-type hHO-1 and its mutant products. After hHO-1 was purified through Ni-column, SDS-PAGE showed a single band with the purity $>95 \%$. lane 1 , molecular weight standards; lane 2, $0.5 \mu \mathrm{g} / \mu \mathrm{l}$; lane $3,1.0 \mu \mathrm{g} / \mu \mathrm{l}$; lane $4,1.5 \mu \mathrm{g} / \mu \mathrm{l}$; lane 5 , $2.5 \mu \mathrm{g} / \mu 1 ;$ lane $6-8,3.0 \mu \mathrm{g} / \mu 1$.
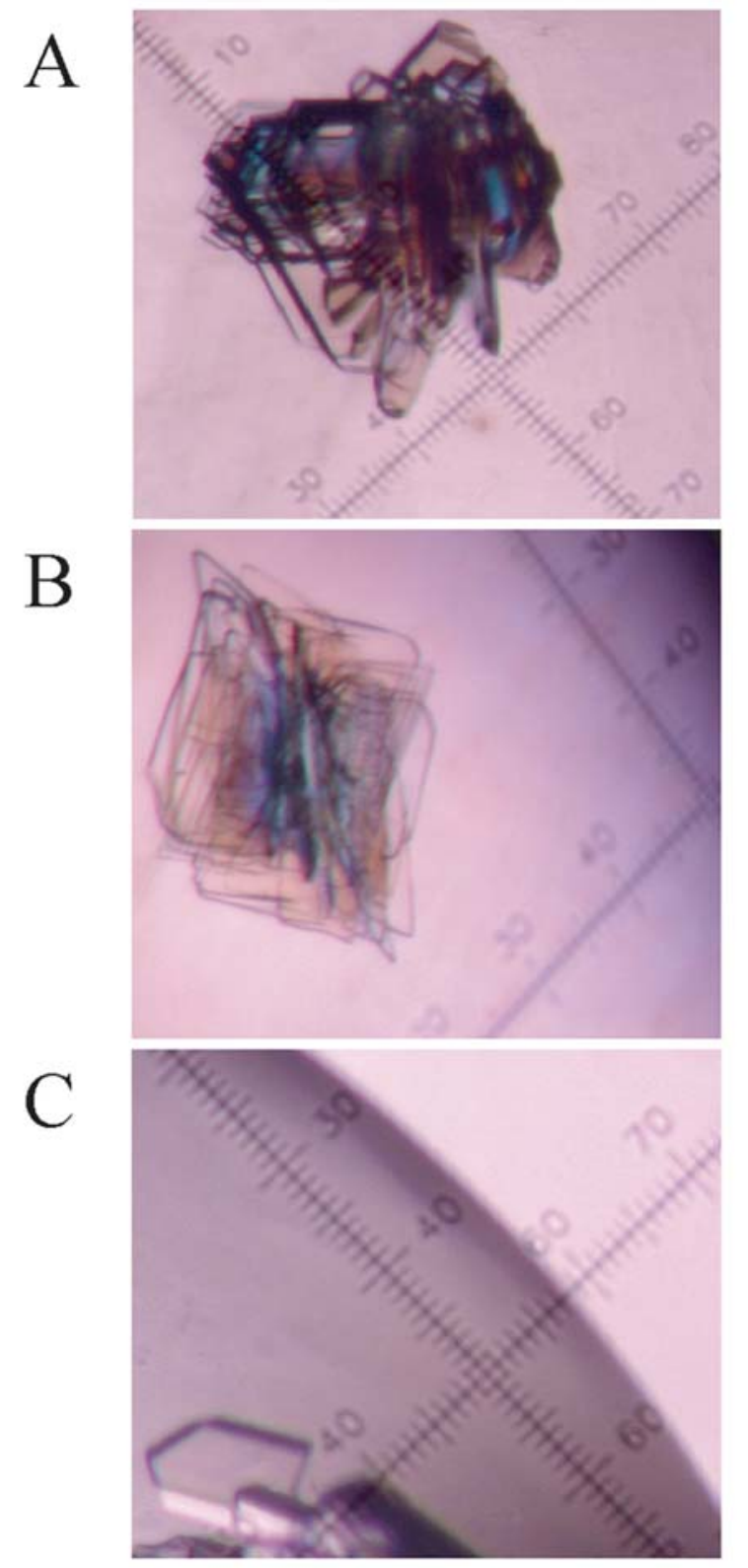

Figure 3. Representative images of His25Ala heme-hHO-1 crystals. (A) In room temperature, multi-layered crystal began to grow approximately one week later, and reached the volume of $0.3 \times 0.35 \times 0.3 \mathrm{~mm}^{3}$ within one month; (B) The crystal cultured at $4^{\circ} \mathrm{C}$ usually required at least one month to reach the size of crystal with thinner layers; (C) Regular-shaped single layer was obtained by cutting to obtain better diffraction data.

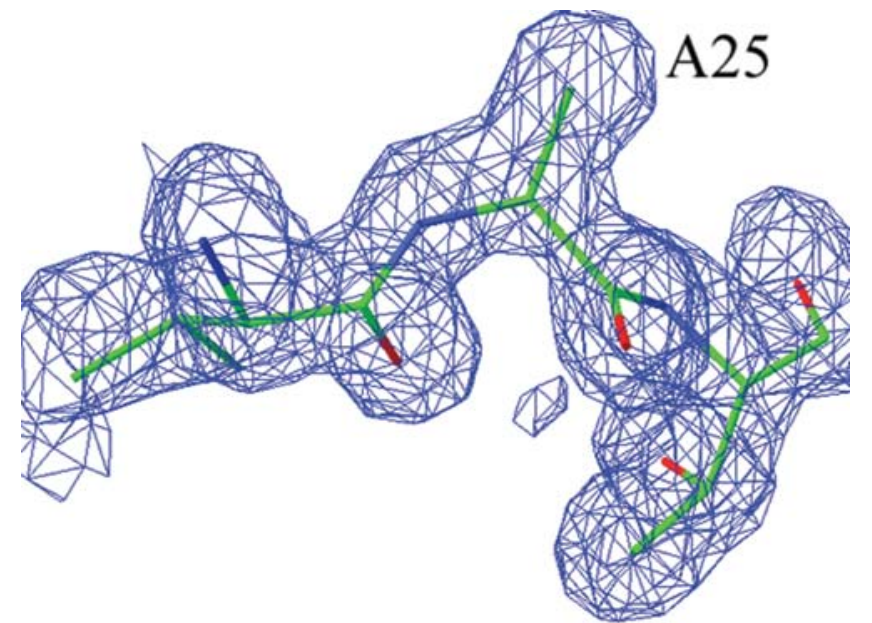

Figure 4. Two Fo-Fc electron density map near Ala25. Good density performance at the ends of side chains in the ( $2 \mathrm{Fo}-\mathrm{Fc})$ electron density map with the contour at $1.5 \sigma$.

and manually adjusted in O program (32). CNS refinement and model building in $\mathrm{O}$ program were repeated until $\mathrm{R} / \mathrm{R}_{\text {free }}$ did not further decline. Then, water molecules were added to the model. The structural analysis was achieved using Procheck (33), CNS and other programs, while the graphics were prepared with the PyMol program (34).

\section{Results}

Construction of short-chain DNA and recombinant expressing plasmid. In order to compare the structure and activity of wildtype and mutant hHO-1, the 710-bp fragment encoded amino acids of wild-type and mutant hHO-1 were constructed in the plasmids pET28b(+)-hHO-1(w) and (m). The insertions were confirmed by $\mathrm{NcoI} / \mathrm{XhoI}$ digestion and sequencing.

Purification of short-chain wild-type hHO-1 and its mutant products. After transfection of the plasmids in DE3 and culture for $18 \mathrm{~h}$, the protein products of the pET28b(+)-hHO-1(w) and (m) were confirmed by SDS-PAGE. Both constructs encoded 233 amino acid residues with a molecular weight of $28 \mathrm{kDa}$. Coomassie blue staining test showed one band and the purity was $>95 \%$. Furthermore, laser dynamic light scattering inspection showed that the purified proteins were well distributed in the solution. Both thermostability and stability of protein were suitable for crystal growth (Figs. 1A,B and 2).

Detection of enzymatic activity of wild-type hHO-1 and its mutant. After generation of both wild-type and mutant hHO-1, we tested and compared their enzymatic activity. Using $\mathrm{NADPH}$ as an electron donor, we measured the activity of wild-type hHO-1 and its mutant. The result showed that the activity of His25Ala hHO-1 mutant was $90.5 \%$ lower than that of wild-type hHO-1. However, by supplementing imidazole, the activity of His $25 \mathrm{Ala}$ hHO-1 mutant was restored to $87.5 \%$ of that in wild-type hHO-1 (Table I).

Crystal culture of His25Ala hHO-1 mutant. In light of the above finding, we then determined whether the mutation altered the protein structure critical for enzymatic activity. To 


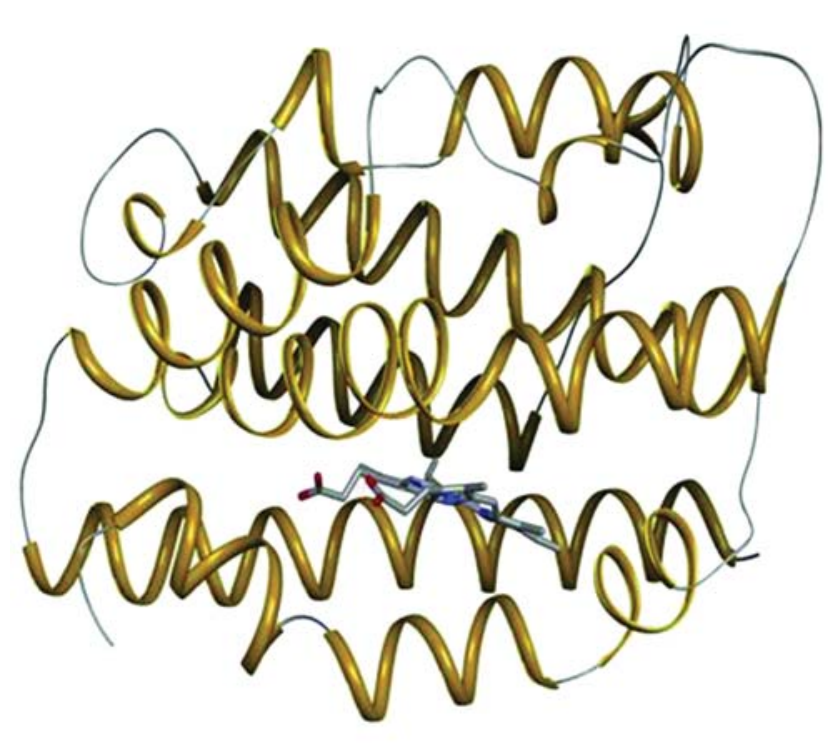

A

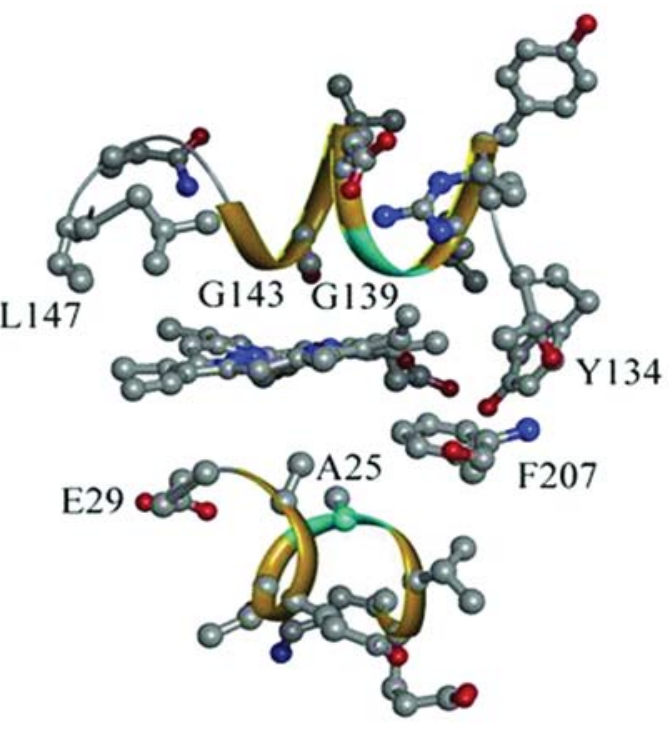

B

Figure 5. The crystal structures of hHO-1. (A) Overall structure of His25Ala mutant and wild-type hHO-1 were similar; (B) Heme pocket was mainly comprised of two helices, proximal and distal. The Ala25 in proximal helix replaced the His 25 in wild-type hHO-1. The proximal helix was farther away from heme. It no longer directly interacted with heme, making the heme pocket larger.

optimize conditions for crystallization, we found that room temperature was a key crystallization condition for His25Ala hHO-1 mutant. In addition, the protein concentration $(40 \mathrm{mg} /$ $\mathrm{ml}$ ), crystallization buffer containing $2.12 \mathrm{~mol} / \mathrm{l}$ ammonium sulfate, $0.1 \mathrm{~mol} / 1 \mathrm{HEPES}$ with $\mathrm{pH}$ of 7.5 and $0.9 \%$ 1,6-isobutanol were all crucial for optimal crystallization. Under these conditions, crystals were obtained directly by X-ray diffraction without complex plantation.

In room temperature, the crystal began to grow $\sim 1$ week later, and reached the volume of $0.3 \times 0.35 \times 0.3 \mathrm{~mm}^{3}$ within one month (Fig. 3A). The crystal data were obtained using $\mathrm{X}$ ray diffraction. The crystal cultured at $4^{\circ} \mathrm{C}$ usually required at least one month to reach the size of crystal with thinner layers as that at room temperature (Fig. 3B), this was unsuitable for data collection. The crystal shape of mutant HO-1 was irregularly multi-layered, larger, and difficult for collecting effective data by direct diffraction at room temperature. However, a regular-shaped, single layer was obtained by cutting (Fig. 3C) for better diffraction data.

Analysis of His25Ala heme-hHO-1 crystal structure. Since His25Ala heme-hHO-1 crystal is monoclinic, space group $\mathrm{P} 2_{1}$, there are four molecules in an asymmetric unit cell. The routine parameters were chosen to analyze the crystal structure. The results showed that the $\mathrm{R}$ factor was 0.245 at $2.8 \AA$ resolution, and the free $\mathrm{R}$ factor was 0.283 . The deviations of bond length and angle to the standard bond length and angle were $0.007 \AA$ and $1.3^{\circ}$ respectively, the dihedral angle was reasonable, the shortest distance between two non-bonding atoms was $>0.3$ $\mathrm{nm}$, carbon atom skeleton and electron density map were well fitted by molecular replacement, optimization of various factors and further adjustment on containing 27,482 protein atoms and 300 water molecules (Table II).

The main chain of His25Ala hHO-1 molecule was also well fitted to the final electron density map. Good density performance at the ends of side chains was found in the (2 FoFc) electron density map with the contour at 1.5 o. Fig. 4 shows the fitting of electron density around Ala25 in the mutant with the model.

Comparison of structures of His25Ala mutant and wild-type hHO-1. After successful establishment of the crystal structures of His25Ala mutant and wild-type hHO-1, the crystal structures were compared. Overall structures of His25Ala mutant and wild-type hHO-1 were similar. The heme pocket was mainly comprised of two helices, proximal and distal. The Ala25 in the proximal helix replaced the His 25 in wild-type hHO- 1 . The proximal helix was further away from heme. Therfore, it no longer directly interacted with heme, making the heme pocket larger. On the other hand, Ala28 and Glu29 were still in contact with heme. The interaction of Ther21 with heme in wild-type hHO-1 was mediated through a water molecule, however, this was not observed in the mutant.

The most apparent feature of wild-type HO-1 structure is the distal deformation that covers the distal heme surface, creating an integrated oxygen-binding pocket (Fig. 5) as previously reported $(29,35)$. The distal helix structure in the mutant was virtually unaffected. Gly139 and 143 in the helix linked to heme directly. They were a part of the highly conserved Gly139-Asp-Leu-Gly-Ser-Gly144 fragment (29). Other residues that interacted with heme were Tyr134, Thr135, Arg136 and Leu147. These amino acid residues were also located in distal without change of spatial positions.

Hydrogen bonds were formed between $\mathrm{N}$ in the His 25 imidazole ring and $\mathrm{O}$ in Glu29 in wild-type hHO-1. This hydrogen bond lacked in the Ala25 mutant because Ala25 did not provide $\mathrm{N}$ for the hydrogen bond. However, other adjacent hydrogen bonding interactions, including those between Ala25 and 28, and between Glu29, Thr21 and Lys22, were intact (Fig. 6). 
Table I. Enzymatic activity of wild-type and mutant hHO-1.

$\begin{array}{cccc}\text { DE3 lysic } & \text { Wild-type } & \text { His25Ala } & \text { His25Ala hHO-1 } \\ \text { supernantant } & \text { hHO-1 } & \text { hHO-1 mutant } & \text { mutant + imidazole }\end{array}$

hHO-1

(nM bilirubin mg protein ${ }^{-1} \mathrm{~h}^{-1}$ )

0.4

23.2

$2.2^{*}$

20.3

Purification

1.0

32.0

31.0

31.0

(fold)

The results represent values from duplicate measurements of three independent experiments. " $\mathrm{p}<0.05$ compared with wild-type hHO- 1 and mutant + imidazole
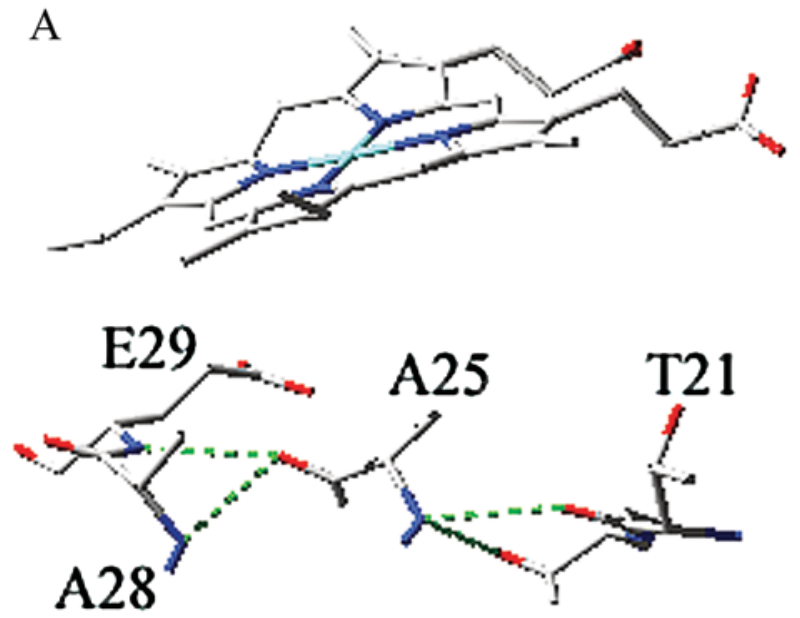

K22
B

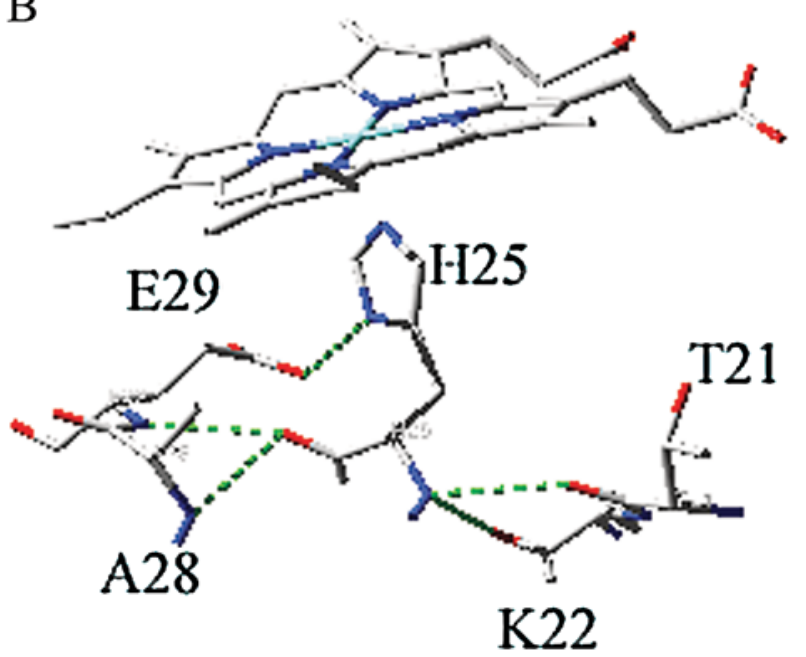

Figure 6. Change of hydrogen bonds due to His25Ala mutation. (A) Ala25 in the mutant lacked N-terminal. Therefore, this hydrogen bond was disrupted. However, other adjacent hydrogen bond interactions including those between Ala25 and 28, and between Glu29, Thr21 and Lys22 were intact; (B) Hydrogen bonds formed between $\mathrm{N}$ in the His 25 imidazole ring and $\mathrm{O}$ in Glu29 in wild-type hHO-1.

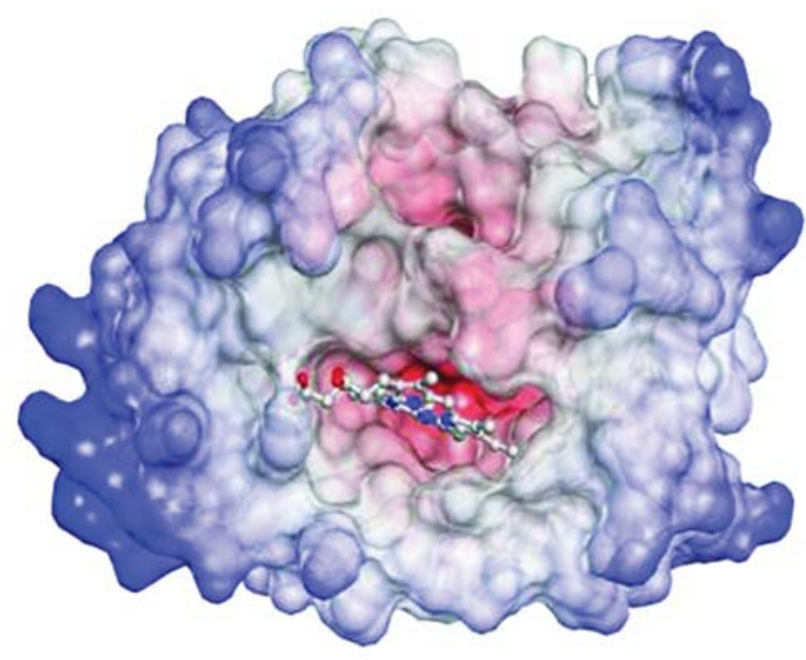

A

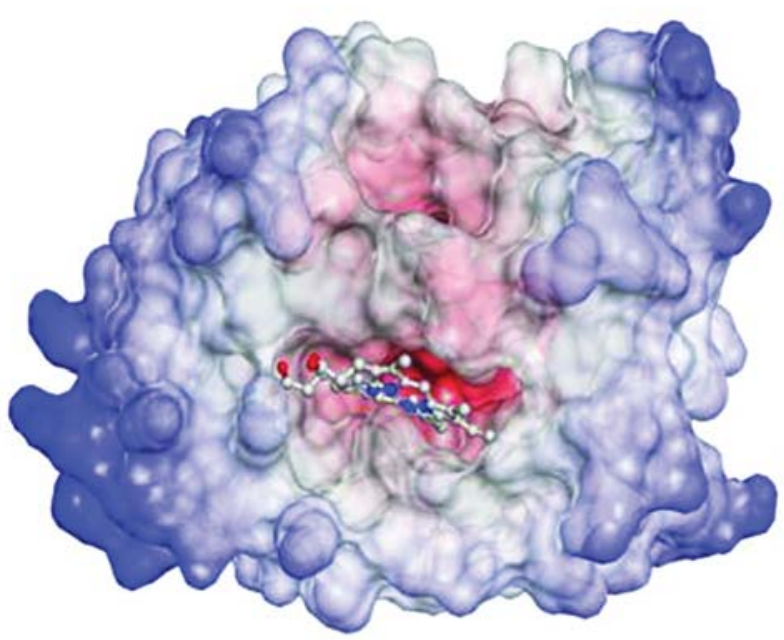

B

Figure 7. Representative images of hHO-1 molecular surface. (A) The molecular surfaces of His $25 \mathrm{Ala}$ mutant and (B) wild-type hHO-1 were of little difference, though the active pocket in the mutant was larger. A positive charge region on the brink of heme was formed around the catalytic reaction pocket. (red, positive charge; blue, negative charge). 
Table II. Diffraction data structure refinement.

His25Ala Heme-hHO-1

\begin{tabular}{|c|c|}
\hline \multicolumn{2}{|l|}{ Crystal data } \\
\hline Radiation source & in house \\
\hline Space group & $\mathrm{P} 2_{1}$ \\
\hline \multicolumn{2}{|l|}{ Cell parameters $(\AA)$} \\
\hline$a(\AA)$ & 60.43 \\
\hline$b(\AA)$ & 71.54 \\
\hline$c(\AA)$ & 94.73 \\
\hline \multicolumn{2}{|l|}{ Data collection } \\
\hline Detector distance (nm) & 160 \\
\hline Moleculars per asymmetirc unit & 4 \\
\hline Resolution $(\AA)$ & 2.8 \\
\hline Mosaicity $\left({ }^{\circ}\right)$ & 0.84 \\
\hline Total observations & 27,482 \\
\hline Unique reflections & 9,854 \\
\hline Completeness (\%) & 98 \\
\hline 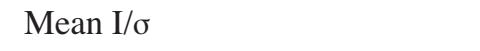 & $1.4(2.2)$ \\
\hline Rmerge $^{1}$ & $0.83(0.301)$ \\
\hline \multicolumn{2}{|l|}{ Refinement statistics } \\
\hline $\mathrm{R}$ factor $^{2}$ & 0.245 \\
\hline free $\mathrm{R}$ factor & 0.283 \\
\hline r.ms.d bond lengths $(\AA)$ & 0.007 \\
\hline r.ms.d. angles $\left({ }^{\circ}\right)$ & 1.3 \\
\hline Water molecules & 300 \\
\hline \multicolumn{2}{|l|}{ Ramachandran angles } \\
\hline Most favored (\%) & 92.7 \\
\hline Additional allowed (\%) & 6.2 \\
\hline Generously allowed (\%) & 0.1 \\
\hline
\end{tabular}

${ }^{1}$ Rmerge $=\sum$ hkl $\sum$ illi(hkl) $-<\mathrm{I}(\mathrm{hkl})>\mathrm{l} / \sum \mathrm{hkl} \sum \mathrm{ili}(\mathrm{hkl})$

${ }^{2} \mathrm{R}$ factor $=\| \mathrm{Fol}-\mathrm{IFcl} / / \mathrm{Fol}$

Overall, the molecular surfaces of wild-type hHO-1 and His25Ala hHO-1 were of little difference, though the active pocket in the mutant was larger. The two had the same substrate affinity in electrostatic potential. A positive charge region on the edge of heme formed around the catalytic reaction pocket (Fig. 7). After mutation, Ala was still located in the surface and did not influence the electrostatic potential of the reaction pocket.

\section{Discussion}

hHO-1 protein contains 288 amino acids and has a molecular weight of $33.0 \mathrm{kDa}$. It is anchored to the reticulum by a Cterminal polypeptide chain consisting of 23 amino acids. As a stress and protective protein, it plays an important role in antioxidation, anti-apoptosis, anti-transplant rejection and other biological functions (36-40). Therefore, studying the structure and function of hHO-1 will enhance our understanding of diseases influenced by HO. Since HO is a membrane-bound protein, it is difficult to isolate it from purified solutions for crystallization and further structural study. As a result, previous studies indirectly used spectrum data. The successful expression of the truncated, soluble and functional form of hHO-1 (lacking the C-terminal 23 amino acids) in E. coli advanced the research of hHO-1 structure and biochemical activities $(41,42)$. This hHO-1 protein is usually composed of 233 amino acids in the final crystal due to hydrolysis. The hydrolysis affects the crystal culture, especially in the crystallization of mutant $\mathrm{HO}-1$, which results in plantation requirement for crystal formation (43-45). In this experiment, we constructed an hHO-1 containing 233 amino acids and its His 25Ala mutant expression plasmid. We achieved high expression in E. coli BL21 strain, up to $60 \mathrm{mg} / \mathrm{l}$. Compared to hHO-1, expressed by DH5 $\alpha$ and consisting of 265 amino acids, the level of hHO-1 expression is 2-fold higher (42). Determined by gel filtration and affinity chromatography, a protein purity $>95 \%$ with high homogeneity was achieved. This approach provides sufficient protein source for analysis of the structure and activity of hHO- 1 .

In this study, we demonstrated that the growth condition for His25Ala hHO-1 protein crystal does not need to be maintained at $28^{\circ} \mathrm{C}(46)$. The crystal grows at room temperature, and it is suitable for X-ray diffraction within one month. Without plantation, the crystal culture is simplified. In addition, the crystal cultured at room temperature has better quality than that cultured at $4^{\circ} \mathrm{C}$; we found that crystals developed at $4^{\circ} \mathrm{C}$ always have thinner layers and are not useful in diffraction.

Spectroscopic analysis and site-directed mutagenesis studies indicate that His 25 is the ligand for heme iron. After mutation of His 25 to Ala25, the activity of protein reduced $\sim 90 \%$. However, by supplementing imidazole, the protein activity resumed $\sim 90 \%$ of the normal level.

The structural analysis of His $25 \mathrm{Ala}$ hHO-1 protein crystal indicates that after replacement of His 25 with Ala, an empty pocket forms below the ferric ion in the heme, leading to a loss of binding iron ligand. Ala replacement does not cause a great change in overall structure. Although formation of hydrogen bonds around the active center is affected, the interaction of other amino acid residues with heme does not change. The impact on the electrostatic potential of the protein molecule surface is also trivial. No obvious change was observed around the active site. Therefore, the interaction of His 25Ala hHO-1 with heme and other substrates could theoretically occur. This is further evident by the fact that the addition of imidazole restores HO-1 activity. His 25 is a neutral imidazole instead of imidazolate. Although His25Ala, a mutant of hHO-1, has a diminished enzymatic activity, its activity is restored by the addition of exogenous imidazole. The results indicate that His 25 site only functions as a catalyst. It does not play a major role in the combination and fixation of heme. However, further investigation is necessary to determine whether His 25 is neutral at all stages of the $\mathrm{HO}$ reaction.

Overall, the structural difference between the wild-type and the His25Ala mutant is small except for the enzymatic active site, which causes the loss of the primary function of catalyzing heme. The loss of activity of His25Ala mutant is caused by the lack of Heme-His 25 coordination, which is necessary for its catalytic effect. Although the overall difference between wild-type and mutant is small, the mutation did affect the hydrogen bond network to some extent. Other reports show 
that the mutation at His 25 disturbs the hydrogen-bonded water cluster near the active site to a larger extent and affected the activity of HO-1 (47-49). This suggests that His25 is crucial to the catalytic function of the enzyme. In addition, the ability to reduce oxidative agents diminish since the interaction between HO-1 and oxidative agents, such as $\mathrm{H}_{2} \mathrm{O}_{2}$, take the same path as it catalyzes the oxidation of heme (47). The availability of structures for both wild-type HO-1 and its various mutants allows further exploration of the dynamics of HO- 1 structure and the differences in their binding abilities to different partners.

\section{Acknowledgements}

This work was supported by grants from the National Natural Science Foundation of P.R. China (Grants 30170988 , 30471833 and 30570798).

\section{References}

1. Tenhunen R, Marver HS and Schmid R: Microsomal heme oxygenase. Characterization of the enzyme. J Biol Chem 244: 6388-6394, 1969.

2. Guzelian PS and Elshourbagy NA: Induction of hepatic heme oxygenase activity by bromobenzene. Arch Biochem Biophys 196: 178-185, 1979.

3. Maines MD: The heme oxygenase system: a regulator of second messenger gases. Annu Rev Pharmacol Toxicol 37: 517-554, 1997.

4. Marilena G: New physiological importance of two classic residual products: carbon monoxide and bilirubin. Biochem Mol Med 61: 136-142, 1997.

5. Rydkina E, Sahni A, Silverman DJ and Sahni SK: Rickettsia rickettsii infection of cultured human endothelial cells induces heme oxygenase 1 expression. Infect Immun 70: 4045-4052, 2002.

6. Cary SP and Marletta MA: The case of CO signaling: why the jury is still out. J Clin Invest 107: 1071-1073, 2001.

7. Vairano M, Dello RC, Pozzoli G, Tringali G, Preziosi P and Navarra P: A functional link between heme oxygenase and cyclo-oxygenase activities in cortical rat astrocytes. Biochem Pharmacol 61: 437-441, 2001.

8. Bauer I, Wanner GA, Rensing H, Alte C, Miescher EA, Wolf B, Pannen BH, Clemens MG and Bauer M: Expression pattern of heme oxygenase isoenzymes 1 and 2 in normal and stressexposed rat liver. Hepatology 27: 829-838, 1998.

9. Zhang F, Kaide JI, Rodriguez-Mulero F, Abraham NG and Nasjletti A: Vasoregulatory function of the heme-heme oxygenasecarbon monoxide system. Am J Hypertens 14: 62S-67S, 2001.

10. Tenhunen R: Method for microassay of microsomal heme oxygenase activity. Anal Biochem 45: 600-607, 1972.

11. Yoshida T and Kikuchi G: Purification and properties of heme oxygenase from pig spleen microsomes. J Biol Chem 253: 4224-4229, 1978.

12. Yoshida T and Kikuchi G: Purification and properties of heme oxygenase from rat liver microsomes. J Biol Chem 254: 4487-4491, 1979.

13. Yoshida T and Kikuchi G: Sequence of heme decomposition by the coupled oxidation of myoglobin with ascorbic acid. Tohoku J Exp Med 115: 67-74, 1975.

14. Scapagnini G, D'Agata V, Calabrese V, Pascale A, Colombrita C, Alkon D and Cavallaro S: Gene expression profiles of heme oxygenase isoforms in the rat brain. Brain Res 954: 51-59, 2002.

15. Muller RM, Taguchi H and Shibahara S: Nucleotide sequence and organization of the rat heme oxygenase gene. J Biol Chem 262: 6795-6802, 1987

16. Morse D and Choi AM: Heme oxygenase-1: from bench to bedside. Am J Respir Crit Care Med 172: 660-670, 2005.

17. Abraham NG and Kappas A: Heme oxygenase and the cardiovascular-renal system. Free Radic Biol Med 39: 1-25, 2005.

18. Alam J, Igarashi K, Immenschuh S, Shibahara S and Tyrrell RM: Regulation of heme oxygenase- 1 gene transcription: recent advances and highlights from the International Conference, Uppsala, 2003 on Heme Oxygenase. Antioxid Redox Signal 6: 924-933, 2004.
19. Yachie A, Niida Y, Wada T, Igarashi N, Kaneda H, Toma T, Ohta K, Kasahara Y and Koizumi S: Oxidative stress causes enhanced endothelial cell injury in human heme oxygenase-1 deficiency. J Clin Invest 103: 29-35, 1999.

20. Poss KD and Tonegawa S: Reduced stress defense in heme oxygenase 1-deficient cells. Proc Natl Acad Sci USA 94: 1092510930, 1997.

21. McCarter SD, Scott JR, Lee PJ, Zhang X, Choi AM, McLean CA, Badhwar A, Dungey AA, Bihari A, Harris KA and Potter RF: Cotransfection of heme oxygenase- 1 prevents the acute inflammation elicited by a second adenovirus. Gene Ther 10 : 1629-1635, 2003.

22. Soares MP, Brouard S, Smith RN and Bach FH: Heme oxygenase-1, a protective gene that prevents the rejection of transplanted organs. Immunol Rev 184: 275-285, 2001.

23. Visner GA, Lu F, Zhou H, Latham C, Agarwal A and Zander DS: Graft protective effects of heme oxygenase 1 in mouse tracheal transplant-related obliterative bronchiolitis. Transplantation 76: 650-656, 2003.

24. Maines MD: The heme oxygenase system and its functions in the brain. Cell Mol Biol 46: 573-585, 2000

25. Sun J, Loehr TM, Wilks A and Ortiz de Montellano PR: Identification of histidine 25 as the heme ligand in human liver heme oxygenase. Biochemistry 33: 13734-13740, 1994.

26. Pond AE, Roach MP, Sono M, Rux AH, Franzen S, Hu R, Thomas MR, Wilks A, Dou Y, Ikeda-Saito M, Ortiz de Montellano PR, Woodruff WH, Boxer SG and Dawson FH: Assignment of the heme axial ligand(s) for the ferric myoglobin, (H93G) and heme oxygenase, (H25A) cavity mutants as oxygen donors using magnetic circular dichroism. Biochemistry 38: 7601-7608, 1999.

27. Hori R, Kashiba M, Toma T, Yachie A, Goda N, Makino N, Soejima A, Nagasawa T, Nakabayashi K and Suematsu M: Gene transfection of H25A mutant heme oxygenase-1 protects cells against hydroperoxide-induced cytotoxicity. J Biol Chem 277: 10712-10718, 2002

28. Xia ZW, Shao J, Shen QX, Wang J, Li YZ, Chen S, Yu SC. The preparation of rat heme oxygenase-1 mutant to reduce the level of bilirubin. Chin Med J 114: 348-351, 2001

29. Schuller DJ, Wilks A, Ortiz de Montellano PR and Poulos TL: Crystal structure of human heme oxygenase-1. Nat Struct Biol 6: 860-867, 1999.

30. Pflugrath JW: The finer things in X-ray diffraction data collection. Acta Crystallogr D Biol Crystallogr 55: 1718-1725, 1999.

31. Brunger AT, Adams PD, Clore GM, DeLano WL, Gros P, Grosse-Kunstleve RW, Jiang JS, Kuszewski J, Nilges M, Pannu NS, Read RJ, Rice LM, Simonson T and Warren GL: Crystallography \& NMR system: A new software suite for macromolecular structure determination. Acta Crystallogr D Biol Crystallogr 54: 905-921, 1998.

32. Jones TA, Zou JY, Cowan SW and Kjeldgaard M: Improved methods for building protein models in electron density maps and the location of errors in these models. Acta Crystallogr A 47: 110-119, 1991.

33. Morris AL, MacArthur MW, Hutchinson EG and Thornton JM: Stereochemical quality of protein structure coordinates. Proteins 12: 345-364, 1992.

34. Delano W: The PyMol Molecular Graphics System. (http:// www. pymol.org) Delano Scientific LLC. San Carlos, 2002.

35. Schuller DJ, Zhu W, Stojiljkovic I, Wilks A and Poulos T: Crystal structure of heme oxygenase from the gram-negative pathogen Neisseria meningitidis and a comparison with mammalian heme oxygenase-1. Biochemistry 40: 11552-11558, 2001.

36. Chu GC, Katakura K, Zhang X, Yoshida T and Ikeda-Saito M: Heme degradation as catalyzed by a recombinant bacterial heme oxygenase, (HmuO) from Corynebacterium diphtheriae. J Biol Chem 274: 21319-21325, 1999.

37. Quan S, Yang L, Abraham NG and Kappas A: Regulation of human heme oxygenase in endothelial cells by using sense and antisense retroviral constructs. Proc Natl Acad Sci USA 98: 12203-12208, 2001.

38. Chang SH, Barbosa TI, Chen C, Kilberg MS and Agarwal A: Glucose deprivation induces heme oxygenase-1 gene expression by a pathway independent of the unfolded protein response. J Biol Chem 277: 1933-1940, 2002.

39. Zhang M, An W and Du HJ: Increased resistance against oxidant-induced injury in the rat vascular smooth muscle cells transfected with human heme oxygenase-1 gene. Sheng Li Xue Bao 54: 12-16, 2002. 
40. Melo LG, Agrawal R, Zhang L, Rezvani M, Mangi AA, Ehsan A, Griese DP, Dell'Acqua G, Mann MJ, Oyama J, Yet SF, Layne MD, Perrella MA and Dzau VJ: Gene therapy strategy for long-term myocardial protection using adeno-associated virus-mediated delivery of heme oxygenase gene. Circulation 105: 602-607, 2002.

41. Ishikawa K, Sato M, Ito M and Yoshida T: Importance of histidine residue 25 of rat heme oxygenase for its catalytic activity. Biochem Biophys Res Commun 182: 981-986, 1992.

42. Wilks A, Black SM, Miller WL and Ortiz de Montellano PR: Expression and characterization of truncated human heme oxygenase, (hHO-1) and a fusion protein of hHO-1 with human cytochrome P450 reductase. Biochemistry 34: 4421-4427, 1995.

43. Lad L, Wang J, Li H, Friedman J, Bhaskar B, Ortiz de Montellano PR and Poulos TL: Crystal structures of the ferric, ferrous, and ferrous-NO forms of the Asp140Ala mutant of human heme oxygenase-1: catalytic implications. J Mol Biol 330: 527-538, 2003.

44. Lad L, Schuller DJ, Shimizu H, Friedman J, Li H, Ortiz de Montellano PR and Poulos TL: Comparison of the heme-free and -bound crystal structures of human heme oxygenase-1. J Biol Chem 278: 7834-7843, 2003.
45. Lad L, Koshkin A, Ortiz de Montellano PR and Poulos TL: Crystal structures of the G139A, G139A-NO and G143H mutants of human heme oxygenase- 1 . A finely tuned hydrogenbonding network controls oxygenase versus peroxidase activity. J Biol Inorg Chem 10: 138-146, 2005.

46. Schuller DJ, Wilks A, Ortiz de Montellano PR and Poulos TL: Crystallization of recombinant human heme oxygenase-1. Protein Sci 7: 1836-1838, 1998

47. Chen H, Moreau Y, Derat E and Shaik S: Quantum mechanical/ molecular mechanical study of mechanisms of heme degradation by the enzyme heme oxygenase: the strategic function of the water cluster. J Am Chem Soc 130: 1953-1965, 2008.

48. Itomaki M, Ishikawa K, Matera KM, Sato M, Ikedasaito M and Yoshida T: Demonstration that histidine-25, but not histidine132 , is the axial heme ligand in rat heme oxygenase-1. Arch Biochem Biophys 317: 253-258, 1995.

49. Ortiz de Montellano PR: The mechanism of heme oxygenase Curr Opin Chem Biol 4: 221-227, 2000. 